\title{
Nanoscale Informal Science Education (NISE) Network Promotes Nanoscience Literacy
}

The scientific community envisions harnessing the unique properties of materials at the nanoscale as a strategy to produce dramatic advances in a broad range of materials-based technologies including medical care, electronics, computing, security, and energy. Realizing this vision depends on our ability to attract the best and brightest students to the physical sciences combined with the willingness of the public sector to provide long-term investments in nanoscale science and engineering research.

In sharp contrast to the scientists' view, popular fiction offers a nightmarish view of nanotechnology's future, most notably

\section{The NISE Team \\ Core Team \\ Museum of Science of Boston Exploratorium (San Francisco) Science Museum of Minnesota}

\section{Organizational Partners Science Centers}

- Oregon Museum of Science and Industry

- New York Hall of Science

- Fort Worth Museum of Science and History

- North Carolina's Museum of Life and Science

- Ithaca Sciencenter

\section{Research Institutions}

- Materials Research Society

- Main Street Science at Cornell University

- University of Wisconsin-Madison Materials Research Science and Engineering Center Interdisciplinary Education Group

- Purdue University's Envision Center for Data Perceptualization

\section{Association of Science-Technology \\ Centers}

In addition, more than 35 Advisors and Thinking Partners from academia, industry, and informal science education (ISE) institutions provide a range of scientific, educational, artistic, and international perspectives to the Core and Organizational Partner teams through NISE Annual Meetings as well as through on-going working group meetings focused on specific project and program development efforts.

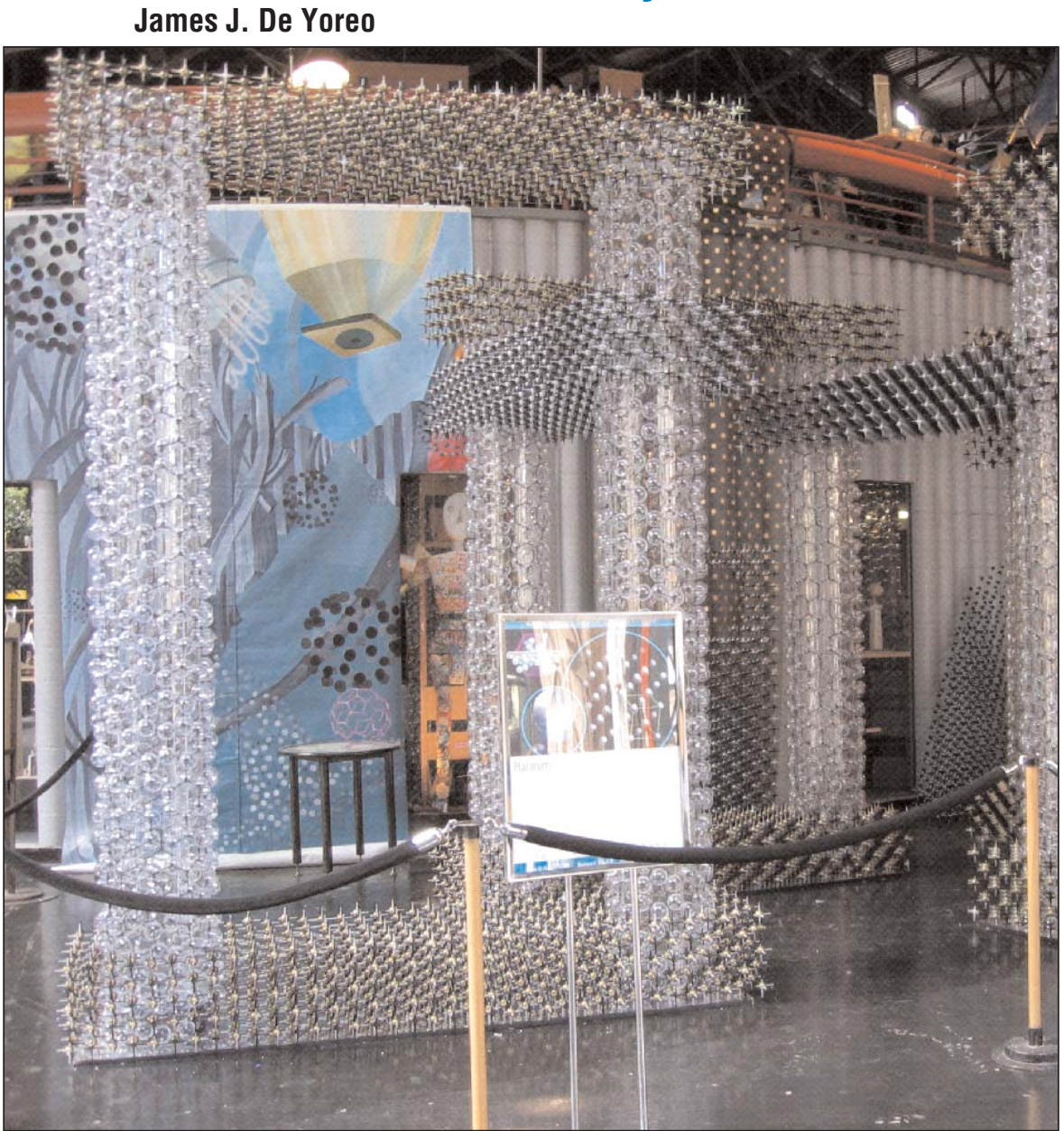

Nanoscape is a NISE exhibit built by Exploratorium personnel and museum visitors in San Francisco over a series of weekends during the summer of 2006.

in Michael Crichton's science fiction book Prey, where research on nanotechnology produces deadly nanobots, which are invisible machines that invade and destroy humans like a virus on steroids.

Even in the absence of public fear about the mortal threat from Crichton's nanobots, neither the hype about nanoscience in the popular press nor our enthusiasm for its potential has done much to remove the shroud of mystery that surrounds the subject amongst the general public. This state of affairs hampers our ability to sustain both the interest and support required to achieve our vision. It is these disparate realities that motivated the Nanoscale Informal Science Education (NISE) network, an initiative funded by the National Science Foundation, to promote the public under- standing of nanoscale science and engineering through informal education.

This five-year, \$20 million initiative has three major goals:

- to foster public awareness, engagement, and understanding of nanotechnology;

- to convey the potential of nanotechnology for revolutionary advances as well as for its everyday relevancy; and

- to capture the imagination of youth who may choose careers in nanoscale science and engineering.

To achieve these goals, NISE has forged a network of science museums and centers working together with the professional research community, creating exhibits, Web sites, workshops, and other activities (see "The NISE Team"). 


\section{Characterizing Materials with Eighth Graders Diane Hickey}

Materials research is interesting. Sometimes it is messy, confusing, frustrating, "wow"-ing, exciting, but always interesting. It is our world around us. So how can we communicate that wonder and that respect to the non-science public in a limited time frame? How, in one hour or less, can a group of 8th graders understand what it is like to be a materials researcher?

For a week in May 2006, I participated in an inquiry-based outreach workshop at the Exploratorium in San Francisco as part of the NISE Nanoscale Educational Outreach (NEO) program to learn how to create nanoscale science outreach projects to interest the public in nanotechnology, while at the same time helping to dispel misconceptions about nanoscale science, engineering, and technology. The NEO workshop is designed to support graduate and postdoctoral scientists, as well as research center education directors, engaged in outreach efforts for their various nanoscale science fields.

This professional development workshop taught skills necessary in creating innovative, engaging, inquiry-based learning activities for many nanoscale outreach activities. In addition, best practices for public communication were stressed to more effectively communicate complex concepts to a general public. Specific topics covered in the workshop included research and theory on learning, diversity issues and strategy, communication and working effectively with teachers, guidelines for writing about science for the general public, and how to design science activities.

Just two weeks after leaving the NEO workshop, I had the opportunity to test what I had learned. I would have two hours to create interest in, and accurately describe, materials science and engineering and nanotechnology to 30 students in middle school.

I must admit, before the NEO workshop, this prospect might have panicked me. Sure, I could get through a half-hour presentation, talking about materials science and engineering, about cool things I do in the laboratory, show some pretty pictures-but it would have been difficult to know whether the students walked away with any strong memories of my presentation.

Armed with what I had learned at the NEO workshop, I simply said my name, said I was a materials scientist, and launched right into an inquiry-based activity characterizing materials.

For this activity, each student was given a plastic bag with a number of "materials" inside- such as paper clips, rubber bands, small ceramics, glass beads, pieces of Styrofoam, and plastic sample containers. The students were told to inspect their materials and write down observations on a sheet of paper. They were instructed to consider questions like, "Does the material feel cold to the touch?" "Does it bend?" "Does it snap back to its original shape after bending?" They were then told to group the items in a logical manner.

Within their groups of four, the students then pooled the materials and talked with other group members to decide on how to "characterize" or "group" the combined materials and nominate a spokesperson to tell the class the outcome.

The students came up with excellent characterizations. Some characterized by optical properties (transparent, opaque), some by flexibility, and some into metals, plastics, and "other." One group even made a Venn diagram!

After every group has presented, I told them that is exactly what materials scientists do when they characterize materials.

Materials scientists characterize a material by its properties.

And the properties tell engineers how to use the material—for example, I asked, would you use an opaque bag for a plastic sandwich bag?

NO! (they replied excitedly) You want to see what's inside.

At this point, I showed a viewgraph about the different areas of materials research, such as metals, polymers, ceramics, electronic properties, and biomaterials. I could see the students nodding their heads, as if to say, "Yeah, that makes sense." And then I could tell the students about metals and racecars, polymers and flexible displays, and electronic properties and computer chips. From there, we moved on to the nano-activities that I had learned from my fellow workshop members at NEO, and very shortly, the two hours were up. Naturally, to end with a bang (and also by demonstrating the effect of a rough surface on nucleating bubbles), we dropped four Mentos into two liters of diet coke to watch it geyser up 20 feet.

It was amazing! The students were engaged, interested, and seemed to understand some of the thinking that went into how we, in materials research, characterize materials and determine their applications.

Diane P. Hickey is a graduate research assistant at SWAMP Center Department of Materials Science and Engineering at the University of Florida. She is studying for her PhD degree in materials science and engineering and also working on a journalism degree.

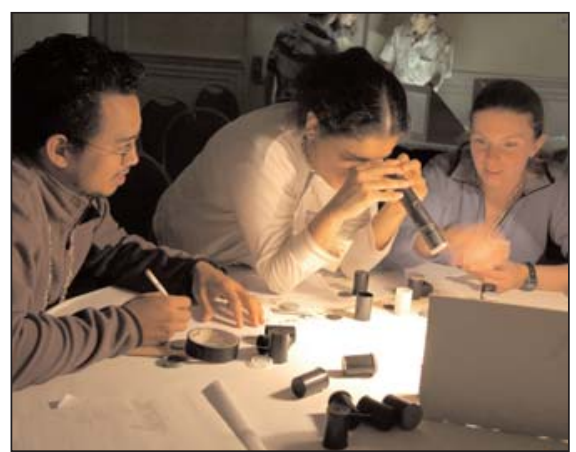

Participants of the NISE NanoEducation and Outreach (NEO) program learn to design science activities.

\section{NISE Activities}

Nanoscape is a NISE exhibit that was built by Exploratorium personnel and museum visitors over a series of weekends during the summer of 2006. Nanoscape consists of a set of model field-effect transistor-based sensors constructed from semiconducting carbon nanotubes (CNTs) and gold and platinum electrodes, all represented with the correct atomic arrangements. During these weekend "builds," materials researchers were on hand to engage the public and answer questions about the unique properties of CNTs and the structure of matter at the nanoscale.

The Nano-Education and Outreach (NEO) program represents one of the NISE activities to promote professional development in communicating science to the public. Through semi-annual fiveday workshops, the NEO program provides graduate students, postdoctoral scientists, and research center education directors with training in inquiry-based education and public communication. Participants are introduced to current theory and research related to science learning with particular attention to issues of diverse student audiences. Participants spend time working on communication skills for non-scientist audiences and, with a partner, design their own inquiry-based activity that they can use in public outreach (see sidebar).

NISE welcomes inquiries and volunteers. To learn more, access the NISE Web site at www.nisenet.org.

James J. De Yoreo of Lawrence Livermore National Laboratory chairs the Materials Research Society NISE Subcommittee. 